\title{
Telefonía móvil en España: regulación y resultados*
}

\author{
Joan Calzada \\ Alejandro Estruch \\ Universitat de Barcelona y GiM-IREA
}

\begin{abstract}
Resumen
En apenas quince años la telefonía móvil ha pasado de ser una actividad marginal a constituir uno de los sectores más dinámicos de la economía española, con niveles de penetración muy elevados. Sin embargo, el crecimiento del mercado no parece haber generado unos niveles de competencia aceptables, ni comparables con los existentes en países similares de nuestro entorno. En este trabajo evaluamos la evolución reciente del sector y proponemos algunas explicaciones para la falta de competencia desde el punto de vista de la economía política, como la laxitud de la regulación y la incapacidad de las autoridades para aumentar el número de operadores. Asimismo, mostramos que la generalización de la banda ancha móvil ofrece un amplio espacio para mantener el crecimiento futuro del sector.

Palabras clave: telefonía móvil, banda ancha, competencia, regulación

Clasificación JEL: D43, L13, L43, L96.
\end{abstract}

\begin{abstract}
In the last 15 years mobile telephony has changed from being a marginal activity to constituting one of the most dynamic sectors of the Spanish economy, with a very high penetration level. However, it seems that the growth of the market has not generated an acceptable level of competition, or one that is comparable with those existing in other European markets with similar features. This paper assesses the recent evolution of the sector and proposes some explanations for this lack of competition from the perspective of the political economy, such as a very permissive regulation with the incumbents and the failure of the authorities to increase the number of operators. We also explain that the spread of mobile broadband services offers a great opportunity to maintain the growth of the sector in the future.

Keywords: mobile telephony broadband, competition, regulation.

JEL classification: D43, L13, L43, L96.
\end{abstract}

\section{Introducción}

La universalización de la telefonía móvil en la década de los noventa ha transformado drásticamente el sector de las comunicaciones y la forma de relacionarse de las personas en muchos ámbitos de la vida. El móvil se ha convertido en un importante factor de crecimiento, que compensa muchas deficiencias de otras infraestructuras, como la falta de conexiones rápidas por carrera o por tren, o los lentos

\footnotetext{
* Los autores agradecen las aportaciones realizadas por un evaluador anónimo. Este trabajo se ha beneficiado del apoyo financiero del Ministerio de Educación (ECO2009-06946ECO) y de la Generalitat de Catalunya (SGR2009-1066).
} 
servicios postales, permitiendo que la información fluya libremente, se reduzcan los costes de transacción y los mercados sean más eficientes.

Hasta mediados de los noventa para la mayoría de españoles los móviles eran artefactos exóticos sólo visibles en el cine o en manos de algunos yuppies. Era una situación comprensible en un país en el que todavía no se había completado la universalización de la telefonía fija tradicional. A partir de la llegada del segundo operador en 1995, no obstante, la telefonía móvil tuvo un desarrollo espectacular. En 2000 el número de líneas de móvil alcanzó al de fijas, en 2003 el gasto en llamadas por móvil superó al de las líneas fijas, en 2005 las líneas móviles con contrato superaron a las de prepago y en marzo de 2006 ya había más móviles que españoles. En 2009 la penetración del móvil fue de 109,3 líneas por cada 100 habitantes, lo cual indica que en la actualidad existen más de 51 millones de líneas (Gráfico 1) ${ }^{1}$. Esta penetración es muy superior a la de la telefonía fija, cerca de 44 líneas por cada 100 habitantes, aunque en este caso suele existir una única línea por hogar. Como resultado de este crecimiento la productividad de los operadores de móvil no ha dejado de aumentar, lo cual les ha llevado a trabajar a escala mundial.

La rápida evolución del sector se ha visto favorecida por el cambio tecnológico. Cada uno de los nuevos estándares que se han adoptado en los últimos treinta años ha dado respuesta a los problemas generados previamente por el aumento de usuarios y de tráfico. Y al mismo tiempo, las mejoras tecnológicas y de gestión del espectro han ayudado a aumentar el número de operadores en el mercado, lo cual ha producido una reducción de precios que ha fomentado la rápida sustitución de la telefonía fija por la móvil.

\section{GRÁFICO 1 \\ PENETRACIÓN DE LA TELEFONÍA FIJA Y MÓVIL EN ESPAÑA}

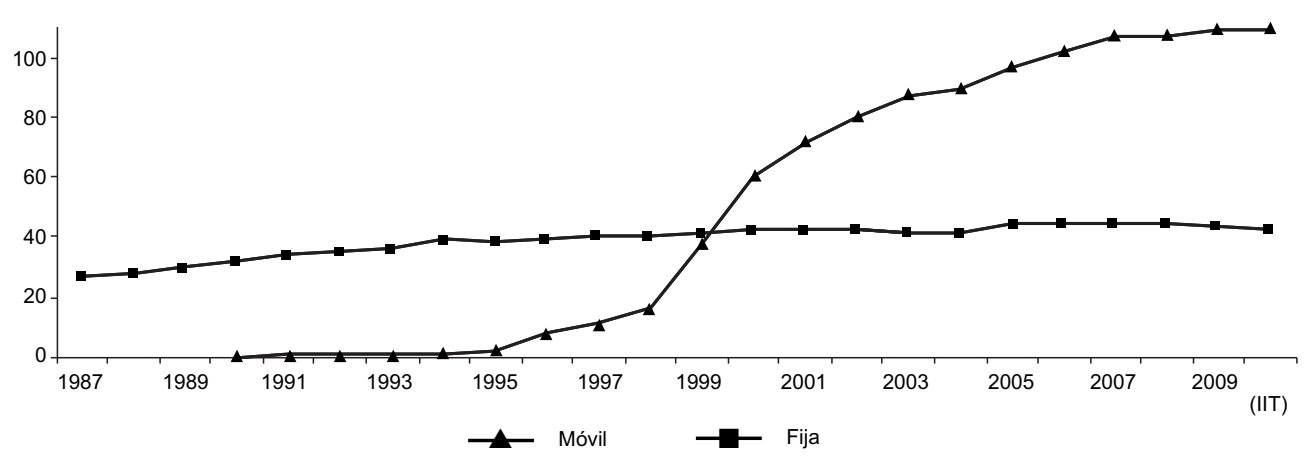

FUENTE: CMT, varios años.

\footnotetext{
${ }^{1}$ La CMT (2010) calcula esta penetración teniendo en cuenta que la población de 2009 era de 46.745.807 habitantes (según el INE). Esta cifra difiere de los 45.828 .172 habitantes (según Eurostat) considerada por la Comisión Europea en el XV informe de la implantación.
} 
El crecimiento del sector medido en términos de ingresos culminó en 2007, cuando por fin entraron en el mercado los operadores móviles virtuales y se intensificó la competencia. En los años anteriores, la reducción en el crecimiento de los usuarios se había compensado con fuertes aumentos de tráfico. Sin embargo, a partir de 2007 el efecto combinado de la reducción del tráfico generado por la crisis económica y las bajadas de precios provocaron que los ingresos totales de la telefonía móvil empezaran a reducirse. Únicamente el servicio de acceso a Internet móvil mantiene el crecimiento de los ingresos, aunque estos no compensan los descensos en los servicios de voz y en los mensajes de texto SMS (Gráfico 2).

El gran crecimiento del móvil no puede disimular, sin embargo, que en los últimos años la competencia ha sido débil, especialmente si comparamos el caso español con el de otros países europeos con unas características similares. En efecto, los precios del móvil se han reducido considerablemente desde 2000, pero los informes de la UE y de la OCDE muestran que los precios en España son de los más altos en el panorama internacional.

Nuestro objetivo en este artículo es mostrar que existen al menos dos explicaciones de la falta de competencia y de los precios elevados en España. La primera es la ausencia de una regulación específica para la telefonía móvil. Durante años las autoridades españolas dieron mucha libertad a los operadores para garantizarles una rentabilidad empresarial que favoreciera la consolidación de la industria nacional. Se desregularon los precios minoristas argumentando que cuando el crecimiento de usuarios se saturase los operadores intensificarían la competencia para atraer clientes. Pero esta situación nunca llegó. Incluso cuando la tasa de penetración del mercado superó el 100 por 100 la migración de tráfico de la telefonía fija a la móvil compensó las reducciones en el crecimiento de usuarios y se evitó la guerra de precios. En los últimos años, la evidencia de que la competencia no se ha desarrollado suficientemente ha llevado a introducir diversas medidas correctoras, como la reducción de los precios de interconexión entre operadores. Sin embargo, la nueva regulación europea del sector, incorporada en la Ley General de Telecomunicaciones de 2003, limita considerablemente la capacidad de actuación de la CMT (Noriega y Ariño, 2004). De este modo, aunque el regulador español está siendo muy activo en regular la interconexión, la nueva normativa prácticamente no le da opciones para intervenir directamente en los precios minoristas. 


\section{GRÁFICO 2}

EVOLUCIÓN DE LOS INGRESOS EN LA TELEFONÍA MÓVIL EN ESPAÑA

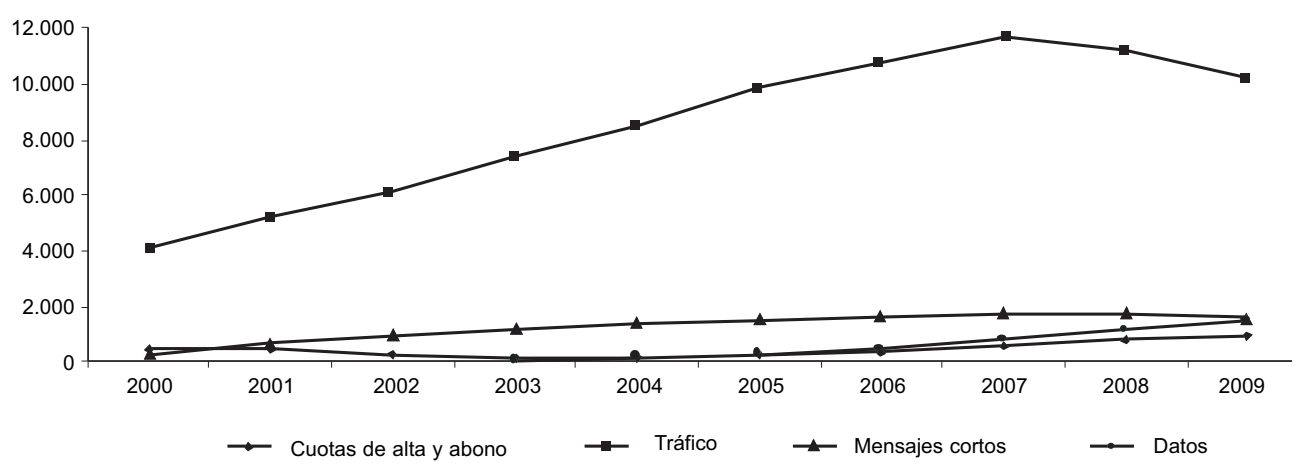

FUENTE: CMT, varios años.

Nuestra segunda explicación de la falta de competencia es la escasa iniciativa de las autoridades públicas para aumentar el número de operadores. En el 2000, sólo existían tres operadores de GSM, pero el mercado se podría haber dinamizado considerablemente con la concesión de las cuatro nuevas licencias de UMTS, y especialmente con la entrada del cuarto operador, Xfera. Sin embargo, los problemas de despliegue de red y de carestía de los terminales provocaron que en toda Europa la $3 \mathrm{G}$ no se pusiera en marcha hasta 2004. La crisis de las puntocom a principios de siglo tampoco ayudó. Y Yoigo (marca de Xfera) no entró en funcionamiento hasta 2008, porque ni el gobierno de José María Aznar ni el de José Luis Rodríguez Zapatero supieron obligar a Xfera a cumplir con sus deberes como adjudicatario.

Tampoco resolvió el problema la regulación de los operadores móviles virtuales (OMVs). Pese a estar permitidos desde 2001, estos operadores no pudieron entrar efectivamente en el mercado hasta que en 2007 se regularon los precios de interconexión. Hasta entonces los precios de interconexión dependían de acuerdos con los operadores con red propia, que tenían escasos incentivos para dejar entrar en el mercado a los OMVs. Esta situación contrasta con la de otros países europeos, donde los OMVs tienen una presencia importante desde hace años y han contribuido considerablemente a impulsar la competencia. Finalmente, la adjudicación de dos nuevas licencias GSM en 2005 tampoco sirvió para introducir nuevos operadores, ya que de nuevo algunas empresas interesadas como Tele2 no lograron llegar a acuerdos de roaming nacional con los operadores establecidos, quienes finalmente se quedaron con el nuevo espectro.

En síntesis, nuestra aproximación desde la economía política indica que las sucesivas regulaciones del móvil en España han buscado dos objetivos contradictorios y perjudiciales entre sí, como son la rentabilidad de los operadores para facilitar su crecimiento y el fomento de la competencia para beneficiar a los usuarios. Es importante destacar que estas contradicciones no se produjeron en la regulación de la tele- 
fonía fija ya que en este caso desde principios de los noventa las autoridades españolas se vieron obligadas a establecer una estricta regulación de los precios para satisfacer el criterio de inflación marcado por el Tratado de Maastricht de 1992 (Calzada y Costas, 2011). Esta presión estuvo siempre acompañada de una intensa actividad reguladora de la CMT para generar competencia. En el móvil, en cambio, la inclusión de los precios en la cesta de comunicaciones del IPC no se produjo hasta el cambio metodológico que dio origen al IPC base 2001 por lo que se refiere tanto a las compras y reparaciones de terminales como a los gastos generados por el uso de móviles. De este modo, nunca existió ni urgencia ni necesidad para reducir los precios, y esto pudo ayudar a los operadores móviles a conseguir una mayor protección de su negocio.

El artículo continúa de la siguiente forma. La sección 2 repasa la evolución del sector desde el monopolio inicial de Telefónica hasta su actual apariencia de competencia oligopolística. En particular nos fijamos en la introducción de las nuevas tecnologías y en su efecto en el número de operadores. La Sección 3 analiza los resultados de la competencia, especialmente en los precios y en la calidad del servicio. La Sección 4 estudia los efectos que se pueden esperar de la irrupción de nuevos servicios a través del móvil, especialmente mediante la implantación de la banda ancha. Finalmente, la Sección 5 termina proponiendo algunas conclusiones.

\section{Del monopolio a la competencia virtual}

A lo largo de las últimas décadas las mejoras tecnológicas de la telefonía móvil han permitido cubrir el fuerte crecimiento de la demanda y mejorar la calidad del servicio ofrecido. A su vez, las nuevas tecnologías y las nuevas formas de organizar el mercado han facilitado la entrada de nuevos operadores.

Las restricciones en el espectro radioeléctrico disponible provocan que el mercado de telefonía móvil se configure necesariamente como un oligopolio restringido. A pesar de ello, en Europa siempre ha habido diferencias en el número de operadores existentes en cada país. También ha habido diferencias en el ritmo en el que se han introducido los nuevos operadores. Gruber (2005) explica que en Dinamarca, Alemania, Grecia y Portugal las primeras licencias se dieron simultáneamente a dos operadores y como consecuencia consiguieron que sus cuotas de mercado fuesen simétricas. En cambio en otros países como España donde la entrada de operadores fue secuencial, los operadores establecidos siempre han mantenido su ventaja respecto a sus rivales. Las ventajas de ser el primer entrante, los costes de cambiar de operador (consumer's switching costs) y la existencia de externalidades de red pueden explicar este fenómeno. 


\subsection{El nacimiento de la telefonía móvil}

La telefonía móvil llegó a España en 1976 de la mano de la Compañía Telefónica Nacional de España (posteriormente Telefónica). La compañía ofrecía el sistema Teléfono Automático en Vehículos (TAV) que operaba en la banda de los $160 \mathrm{MHz}$. A través de técnicas de radiotelefonía rudimentarias se ofrecía servicio en Madrid y Barcelona a precios exorbitados y mediante receptores que eran tan pesados que tenían que ser instalados en vehículos ${ }^{2}$. Posteriormente, durante el mundial de fútbol de 1982 Telefónica puso en funcionamiento la telefonía móvil celular, basada en el estándar Nordic Mobile System (NMS). Este sistema operaba en la banda de 450 $\mathrm{MHz}$ y tuvo mucho éxito ya que las baterías pesaban menos y los terminales se podían transportar en unos maletines ${ }^{3}$. Hacia 1990 el NMT-450 se extendió a todas las provincias y llegó a los 55.000 abonados (Sancho, 1999; Romeo y Huidobro, 2006).

Sin embargo, la congestión del espectro radioeléctrico llevó a la compañía a implantar en 1990 el sistema Total Access Comunication System (TACS-900), mucho más potente y que operaba en la banda de $900 \mathrm{MHz}$. Telefónica optó por esta tecnología analógica a pesar de que en 1987 el Consejo Europeo había recomendado utilizar la tecnología digital, y que España había aceptado adoptarla en la Conferencia Europea de Correos y Telecomunicaciones (CEPT). Al igual que otros operadores europeos (como el británico, el irlandés o el italiano), Telefónica consideró que el TACS-900 ya suponía un enorme avance tecnológico y que por el contrario la tecnología digital todavía no estaba bien desarrollada (MOPTMA, 1994; Alabau, 2001).

Según Gruber (2005), los altos precios que Telefónica impuso en esta época explican el menor desarrollo del servicio en España en comparación con el de otros países europeos. Con todo, el TACS-900 fue sustituido en pocos años debido a varios problemas, como su falta de interoperabilidad. En efecto, para conseguir que todos los sistemas de todos los países europeos fuesen compatibles y posibilitar el roaming internacional el Groupe Spéciale Mobile (posteriormente rebautizado como Global System for Mobile Telecommunications, GSM) desarrolló un estándar no propietario e interoperable para la telefonía móvil celular diseñado para operar en la banda de 900 y $1.800 \mathrm{MHz}$. La Unión Europea consideró necesario que todos los operadores europeos adoptasen este estándar y fomentó que se investigara para mejorarlo. Motorola, Ericsson y Nokia desarrollaron las patentes más importantes para este estándar, y acabaron dominando el mercado junto con otras empresas europeas como Siemens y Alcatel.

${ }^{2}$ La primera aparición de este tipo de servicio integrado en los coches la realizó AT\&T en 1947 cuando lo lanzó en la autopista que une Boston y Nueva Cork (AGAR, 2003).

3 Según GRUBER y VALLETTI (2003), la telefonía móvil automática que utiliza una estructura celular fue desarrollada en 1973 por Martin Cooper en Motorola y empezó a comercializarse por NTT DoCoMo en Tokio en 1979. En Estados Unidos, la Federal Communications Comisión inició la subasta de licencias de telefonía móvil en las ciudades antes de la ruptura del Bell System. Estas subastas tuvieron tanto éxito que la FCC decidió asignar directamente las licencias a las 30 ciudades más grandes y repartir el espectro en el resto a través de loterías. 


\subsection{La llegada de la telefonía digital y el lanzamiento del segundo operador}

La aparición del GSM ayudó a introducir competencia en el mercado. En España la liberalización del móvil se inició en 1992 cuando el gobierno del PSOE reformó la Ley de Ordenación de las Telecomunicaciones de $1987^{4}$ para adaptarla a las nuevas directrices liberalizadoras de la Comisión Europea en materia de competencia en los mercados de equipos terminales y de servicios de valor añadido. La LOT instauró un régimen de competencia restringida en los servicios de radiobúsqueda y radiocomunicaciones móviles terrestres en grupos cerrados de usuarios (trunking), estableciendo así los primeros pasos para la liberalizar el servicio. A su vez definió a la telefonía móvil como un servicio de valor añadido, y previó la concesión de una segunda licencia de móvil mediante el sistema GSM antes del 31 de diciembre de 1993. Este plazo no se llegó a cumplir debido al enfrentamiento en el seno del gobierno entre Pedro Solbes, ministro de Economía y defensor de conceder varias licencias para reducir el dominio de Telefónica, y Josep Borrell, ministro responsable del sector y partidario de crear un duopolio que asegurase que Telefónica tuviese suficientes recursos para financiar la universalización de la telefonía fija, auténtica prioridad del ministro en aquel periodo (Calzada y Costas, 2011).

Al contrario de lo que ocurriría en la telefonía fija, en el móvil la estrategia de Borrell de una liberalización lenta y controlada fue la que acabó imponiéndose. De este modo, en julio de 1994 se aprobó el Reglamento de prestación del servicio de telefonía móvil ${ }^{5}$, que establecía que la modalidad GSM se debía ofrecer en régimen de competencia. Esto suponía la creación de un mercado dual: monopolio de Telefónica en el móvil analógico hasta 2007 -aunque Moviline finalmente se liquidó en $2003^{6}$ - y duopolio en el móvil digital -con Movistar y un segundo operador-. Esta medida equiparaba a España con los mercados europeos más competitivos ya que en 1993 solo existían dos operadores de telefonía celular en Alemania, Dinamarca, Francia, Grecia, Italia, Portugal y el Reino Unido. El resto de países europeos sólo tenían un operador.

El mecanismo para otorgar la segunda licencia tampoco estuvo exento de controversia. En el MOPTMA Borrell era partidario de utilizar el sistema de subasta pública, en el que se incluyese un pago por la utilización del espectro radioeléctrico, así como compromisos de cobertura del servicio, inversiones y empleo. La industria, por el contrario, defendía el concurso de méritos, apoyado también por el vicepresidente Narcís Serra, interesado en la creación de núcleos duros de capital nacional. Finalmente el Consejo de Estado, llamado a intervenir, se decantó por el concurso, pero impuso la separación contable del negocio móvil de Telefónica.

\footnotetext{
${ }^{4}$ Ley 32/1992, de 3 de diciembre, de modificación de la Ley 31/1987, de 18 de diciembre, de ordenación de las telecomunicaciones.

5 Real Decreto 1486/94 de 1 de julio.

6 La Transitoria Tercera del RD 1486/94 fijaba como límite para el final del servicio el 31 de diciembre de 2006, pero a petición de Telefónica la Secretaría de Estado de Telecomunicaciones y para la Sociedad de la Información la adelantó al 31 de diciembre de 2003.
} 
Al concurso se presentaron casi cuarenta empresas que se agruparon después en cinco consorcios. Airtel (Vodafone desde 2001) ganó el concurso y pagó 510,8 millones de euros por una licencia que Telefónica consiguió sin coste alguno. Como consecuencia, la Comisión Europea consideró que se había producido un trato de favor hacia Telefónica e instó al Gobierno a compensar a Airtel. De este modo, durante unos años se concedió a Airtel una reducción del 50 por 100 en el precio de la interconexión y en el canon por el uso de espectro radioeléctrico. Airtel empezó su actividad comercial en 1995 a través de la red de Retevisión, con una estrategia mixta orientada a la prestación de servicios y a la venta de terminales.

La creación de este duopolio coincidió con el proceso de arranque del sector. Tanto Telefónica como Airtel consiguieron los recursos necesarios para expandir su red, beneficiándose a la vez de las externalidades de red del nuevo servicio y del abaratamiento de los terminales causado por la rápida pulsión de la demanda.

\subsection{El tercer operador y la expansión del sector}

En enero de 1996 la Directiva europea 92/2 fijó el 1 de enero de 1998 como fecha límite para conceder las frecuencias de espectro radioeléctrico que debían permitir utilizar el estándar GSM, a través del sistema Digital Cellular System (DCS-1800), que operaba en la banda de $1.800 \mathrm{MHz}$. Inicialmente el Gobierno socialista se opuso a esta nueva apertura del mercado ante el Tribunal de Justicia Europeo, alegando la falta de competencias de la Comisión en este tema (Alabau, 1998). Sin embargo, ante el carácter irremediable de la situación, cuando el Partido Popular ganó las elecciones en 1996 decidió liberalizar rápidamente el sector como estrategia para adelantarse al resto de países europeos y beneficiar a la industria nacional.

En pleno proceso de expansión del servicio el primer gabinete Aznar tuvo que decidir sobre dos aspectos centrales para el desarrollo de la segunda generación de móvil: cómo regular los precios y cuántos operadores introducir en el mercado. En cuanto a los precios, el gobierno esperaba que la competencia entre los operadores existentes hiciera innecesaria la regulación, y por ello la suprimió en 1998. Vista en perspectiva, parece que la decisión de desregular los precios fue precipitada, pero a pesar de todo entre 1998 y 1999 el precio medio de la telefonía móvil se redujo un 17,8 por $100^{7}$. Respecto al número de operadores, inicialmente el ministerio de Fomento planteó que debían existir en el mercado tres operadores nacionales y diversos operadores regionales. Esta era la estrategia que estaban adoptando otros países europeos, un modelo ideal para los nuevos operadores de cable españoles porque podían conseguir una licencia para su demarcación. Sin embargo, finalmente en 1997 Rafael Arias-Salgado, ministro de Fomento, sólo autorizó la entrada de un tercer operador de ámbito nacional que debía competir con Movistar y Airtel.

\footnotetext{
${ }^{7}$ Entre 1995 y 1998 la tasa de penetración pasó del 2,3 por 100 al 16,3 por 100, es decir, se multiplicó por 7 .
} 
La tercera licencia fue sacada a concurso y adjudicada a Retevisión móviles ${ }^{8}$, que empezó a operar en enero de 1999 bajo la marca Amena (Orange desde 2006). Para que Amena se pudiera consolidar en el mercado se estableció que Movistar y Airtel no pudieran usar el GSM-1800 durante seis meses y que debían dar acceso a sus redes a su nuevo rival. La llegada de Amena al mercado fue fulgurante. Entre 1998 y 1999 la penetración del móvil en España aumentó del 16,3 al 38,1 por 100 y Amena logró un número importante de clientes. Además Airtel elevó su cuota de mercado del 25 al 33 por 100, erosionando todavía más la posición de Telefónica (Gráfico 3).

\section{GRÁFICO 3}

CUOTAS DE MERCADO DE LOS OPERADORES ESPAÑOLES

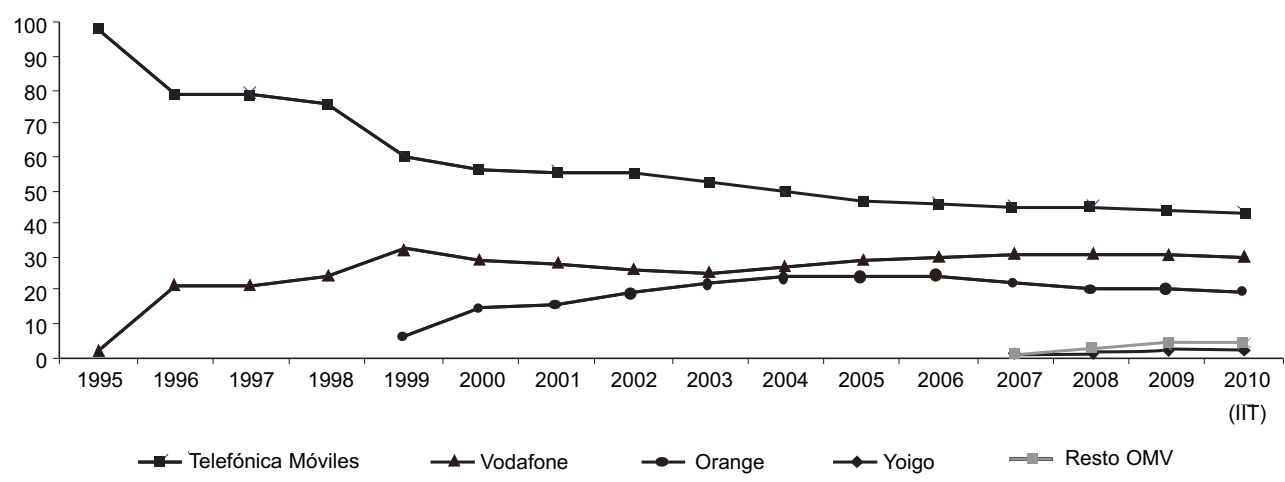

FUENTE: CMT, varios años.

\section{GRÁFICO 4}

CUOTAS DE MERCADO DEL PRIMER Y TERCER OPERADOR EN LA UE, 2008

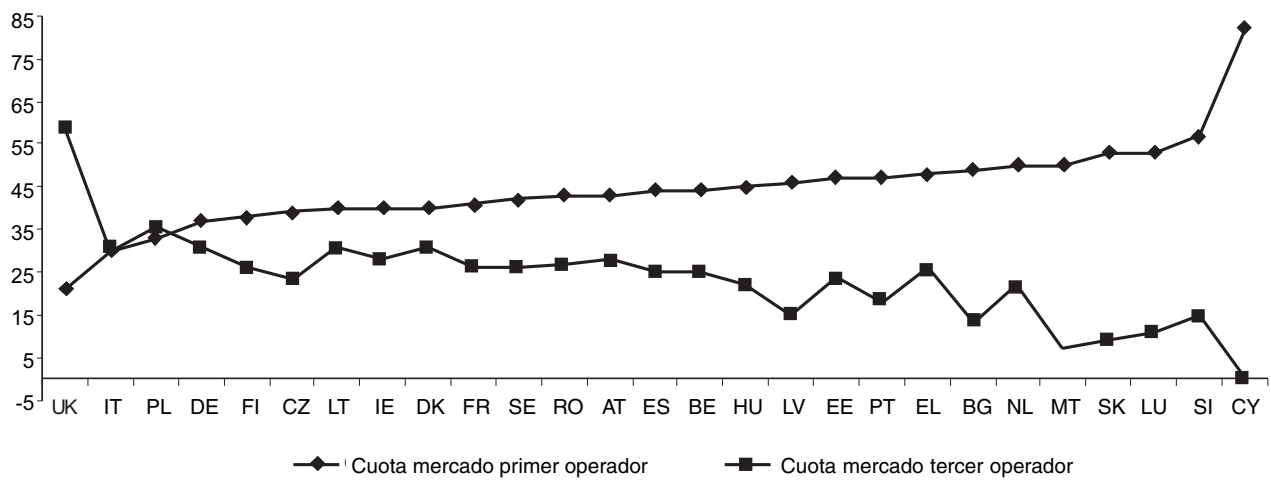

FUENTE: European Comission (2010).

\footnotetext{
${ }^{8}$ Retevisión (Telecom Italia) tuvo que enfrentarse a Alas (France Télécom, Banco Santander y Ferrovial). Las dos empresas de telefonía fija aspiraban a obtener una licencia para convertirse en operadores globales que pudiesen competir en igualdad de condiciones con Telefónica (SANZ, 1999).
} 
No hay duda de que la concesión de la segunda licencia DCS-1800 a Airtel en 1995 y de la tercera a Amena en 1999 aumentó el dinamismo del mercado español. Aun así, es importante resaltar que en 2005 la cuota de mercado de Telefónica Móviles aún era de casi el 50 por 100 y que en los siguientes años continuó siendo alta en relación a la de otros países europeos (Gráfico 4). Según los estudios de la Comisión Europea, en los países en los que a finales de los noventa se concedió una cuarta licencia de GSM el peso del operador principal fue ostensiblemente menor.

\subsection{La precipitación europea en el lanzamiento de la tercera generación}

Pero mientras en España se estaba concediendo la tercera licencia de $2 \mathrm{G}$, las autoridades europeas ya estaban preparando la llegada de la $3 \mathrm{G}$ para finales de los noventa. Desde mediados de los noventa la International Telecommunications Union (ITU) había impulsado un estándar global para 3G a través de la iniciativa IMT-2000 con el objetivo de mejorar el sistema de transmisión de datos y facilitar la transmisión de Internet a alta velocidad (Gruber, 2005). La ITU aceptó cinco sistemas de la familia de estándares IMT-2000, tres de los cuáles están basados en el Code Division Multiple Access (CDMA). En Europa, el European Telecommunications Standardisation Institute (ETSI) promovió la adopción del W-CDMA, conocido por Universal Mobile Telecommunication System (UMTS). Un aspecto fundamental de este estándar es que inicialmente era compatible con el GSM pero incompatible con el estándar americano de 3G. En la actualidad, no obstante, los proveedores de servicios buscan la compatibilidad con todos los estándares existentes (Salant y Waverman, 1998; Cabral y Salant, 2009).

España fue uno de los países que se interesaron más pronto por la $3 \mathrm{G}$. A finales de los años noventa había calado la idea de que uno de los pilares del éxito económico europeo era el crecimiento de la telefonía móvil digital sustentada en el GSM. Este éxito del GSM llevó al gobierno de José María Aznar a querer que las empresas españolas de telecomunicaciones y electrónica fuesen las primeras en adoptar la nueva tecnología, de manera similar a como lo habían logrado antes Nokia y Ericsson para el GSM. Confiaba que el éxito del móvil ayudaría a la modernización de la economía española y al desarrollo de la Sociedad de la Información (Calzada y Costas, 2011).

Con estas expectativas, en 1999 el Gobierno convocó el concurso para otorgar cuatro licencias UMTS y el 13 de marzo de 2000 adjudicó las licencias, convirtiéndose así en el segundo país europeo en hacerlo, después de Finlandia. Aunque se presentaron al concurso dieciséis empresas agrupadas en seis entidades, se dio una licencia a cada uno de los operadores de GSM existentes. La cuarta licencia fue para Xfera (posteriormente Yoigo) que no recibió ningún apoyo oficial para que pudiera negociar acuerdos de interconexión con los operadores establecidos (al contrario de lo ocurrido anteriormente con Airtel y Amena). Las empresas de móvil españolas pagaron en total cerca de 523 millones de euros, y se fijó el 1 de agosto de 2000 como fecha en la que debían empezar a operar en las ciudades de más de 250.000 habitantes.

Sin embargo, la puesta en marcha del UMTS se acabó retrasando varios años porque no estaban disponibles ni los terminales ni muchas especificaciones técnicas 
que habían de ayudar a crear las nuevas redes. De hecho, las licencias de UMTS se concedieron cuando ni siquiera se habían hecho pruebas de la tecnología. De este modo el lanzamiento del 3G, lejos de reforzar el liderazgo europeo en el mundo, acabó suponiendo un lastre para los operadores en sus mercados nacionales.

Ante los retrasos que se acumulaban la CMT recomendó impulsar el sistema GPRS, que presta servicios similares a los del UMTS pero aprovechando las redes GSM. La intención era crear demanda futura para las nuevas aplicaciones de la telefonía móvil. En estas circunstancias el ministerio de Fomento aceptó retrasar la entrada en funcionamiento del UMTS hasta junio de 2002. En realidad, las primeras tarjetas duales UMTS/GPRS se pusieron a la venta por Vodafone en febrero de 2004 (alternaban entre los dos sistemas según la cobertura disponible) y sólo podían usarse en ordenadores porque los teléfonos UMTS no llegaron hasta unos meses después.

\section{CUADRO 1}

SUBASTAS Y CONCURSOS EN EUROPA ENTRE 2000 Y 2001

\begin{tabular}{|c|c|c|c|c|c|}
\hline País & $\begin{array}{l}\text { Número y tipo } \\
\text { de licencias }\end{array}$ & $\begin{array}{c}\text { Operadores } \\
\text { ganadores }\end{array}$ & $\begin{array}{l}\text { Recaudación } \\
\text { (millones €) }\end{array}$ & $\begin{array}{c}\text { Adjudicación } \\
\text { licencia }\end{array}$ & $\begin{array}{l}\text { Desarrollo } \\
\text { comercial }\end{array}$ \\
\hline \multicolumn{6}{|c|}{ Subastas } \\
\hline Reino Unido & $\begin{array}{l}5 \text { licencias } \\
\text { nacionales }\end{array}$ & $\begin{array}{l}\text { Orange, Vodafone, } \\
\mathrm{O} 2,3 \text {-Hutchinson, } \\
\text { T-Mobile }\end{array}$ & 37.188 & Abril 2000 & Febrero 2004 \\
\hline Alemania & $\begin{array}{l}2 \text { tramos } 2 \times 5 \mathrm{MHz} \\
\text { adjudicadas a } \\
6 \text { operadores }\end{array}$ & $\begin{array}{l}\text { T-Mobile, O2, } \\
\text { E-Plus Vodafone, } \\
\text { MobilCom, } \\
\text { QUAM (Group 3G) }\end{array}$ & 50.490 & Agosto 2000 & Mayo 2004 \\
\hline Italia & 5 nacionales & $\begin{array}{l}\text { Vodafone, IPSE } \\
\text { 2000, TIM, Wind, } \\
\text { 3-Hutchinson }\end{array}$ & 12.161 & Octubre 2000 & Mayo 2004 \\
\hline \multicolumn{6}{|c|}{ Concursos } \\
\hline España & 4 nacionales & $\begin{array}{l}\text { Telefónica Móviles, } \\
\text { Vodafone, Amena, } \\
\text { Xfera }\end{array}$ & 523 & Marzo 2001 & Mayo 2004 \\
\hline Francia & 4 nacionales & $\begin{array}{l}\text { Orange France, } \\
\text { SFR, Bouygues } \\
\text { Telecom }\end{array}$ & 1.857 & Junio 2001 & Junio 2004 \\
\hline Suecia & $\begin{array}{l}4 \text { licencias nacio- } \\
\text { nales de } 2 \times 15 \mathrm{MHz} \\
\text { y una de } 5 \mathrm{MHz} \\
\text { por operador }\end{array}$ & $\begin{array}{l}\text { Vodafone, Sun AB, } \\
\text { Orange, } \\
3 \text { (Hutchinson) }\end{array}$ & 0,004 & Diciembre 2000 & Mayo 2003 \\
\hline Portugal & $\begin{array}{l}4 \text { licencias } \\
\text { nacionales }\end{array}$ & $\begin{array}{l}\text { TMN, Vodafone, } \\
\text { Optimus, Oniway }\end{array}$ & 400 & Diciembre 2000 & Abril 2004 \\
\hline
\end{tabular}

FUENTE: PRAT y VALLETTI (2003) y FUENTELSAZ et al. (2008). 
CUADRO 2

LICENCIAS DE TELEFONÍA MÓVIL EN EUROPA

\begin{tabular}{|c|c|c|c|}
\hline & $\begin{array}{l}\text { Número de } \\
\text { operadores con } \\
\text { GSM, } 2005\end{array}$ & $\begin{array}{l}\text { Cuota mercado } \\
\text { clientes operador } \\
\text { principal, } 2005\end{array}$ & Licencias con UMTS \\
\hline Alemania & 4 & 31 & $\begin{array}{l}2 \text { tramos de } 2 \times 5 \mathrm{MHz} \text { adjudicadas a } \\
6 \text { operadores en la primera etapa }\end{array}$ \\
\hline Austria & 4 & 40 & $\begin{array}{c}2 \text { tramos de } 2 \times 5 \mathrm{MHz} \text { adjudicados a } \\
6 \text { operadores }\end{array}$ \\
\hline Bélgica & 3 & 47 & $\begin{array}{c}4 \text { nacionales } \\
\text { 2x15 MHz por operador más } \\
5 \mathrm{MHz} \text { emparejada }\end{array}$ \\
\hline Dinamarca & 4 & 31 & 4 nacionales \\
\hline España & 3 & 48 & 4 nacionales \\
\hline Finlandia & 3 & 46 & 4 nacionales \\
\hline Francia & 3 & 47 & 4 nacionales \\
\hline Grecia & 4 & 41 & Entre 3 y 5 nacionales \\
\hline Irlanda & 3 & 49 & 4 nacionales \\
\hline Italia & 3 & 40 & 5 nacionales \\
\hline Luxemburgo & 2 & 58 & 4 nacionales \\
\hline Países Bajos & 5 & 36 & $\begin{array}{c}5 \text { nacionales }(3 \text { de } 2 \times 10+5 \mathrm{MHz} \\
\text { y } 2 \text { de } 2 \times 15+5 \mathrm{MHz})\end{array}$ \\
\hline Portugal & 3 & 52 & 4 nacionales \\
\hline Reino Unido & 4 & 25 & 5 nacionales \\
\hline Suecia & 4 & 45 & $\begin{array}{c}4 \text { licencias nacionales de } \\
2 \times 15 \mathrm{MHz} \text { más una adicional de } \\
5 \mathrm{MHz} \text { por cada operador }\end{array}$ \\
\hline
\end{tabular}

FUENTE: Elaboración propia partir de PRAT y VALLETTI (2003) y COMISIÓN EUROPEA (2006). 
En España la precipitación en la adjudicación de las licencias tuvo otras consecuencias. El gobierno recibió duras críticas por la escasa recaudación obtenida al utilizar el procedimiento del concurso, en lugar de las subastas. En efecto, otros países como Alemania o el Reino Unido que adjudicaron las licencias a través de subastas obtuvieron ingresos mucho mayores (Cuadro 1). Anna Birulés, la nueva ministra de Ciencia y Tecnología argumentó entonces que los menores precios de las licencias en España acabarían ofreciendo más inversiones y menores precios ${ }^{9}$. No obstante, en los años siguientes cundió el descontento en la opinión pública al evidenciarse que los precios no bajaban y que los beneficios de los operadores crecían considerablemente ${ }^{10}$. A esto hay que sumar el clamor social por los supuestos efectos de la telefonía móvil en la salud, lo cual llevó a muchos ayuntamientos a paralizar la concesión de permisos de obra para la instalación de antenas y otras infraestructuras. Todo esto produjo la sensación de que la política regulatoria sobre el móvil había perdido el rumbo.

Por si esto fuera poco, meses después de la concesión de las licencias de UMTS en Europa el sector de las telecomunicaciones vivió una grave crisis económica. La denominada crisis de las puntocom apareció al desvanecerse las expectativas que los mercados financieros habían puesto en las telecomunicaciones, y en especial en Internet. Así, por ejemplo, entre marzo de 2000 y octubre de 2002 la bolsa de tecnológicas Nasdaq de Nueva York perdió un 60 por 100 de su valor, pasando de 13.000 a 5.000 puntos. En este periodo desaparecieron miles de empresas del sector en todo el mundo y esto, junto con las grandes sumas de dinero que los operadores tuvieron que pagar en las subastas europeas, frenó la inversión en nuevas redes ${ }^{11}$. Los operadores preferían utilizar sus redes amortizadas antes de desplegar nuevas redes de 3G. Así, por ejemplo, en España entre 2000 y 2003 las inversiones de los operadores pasaron del 24 al 6 por 100 de sus ingresos, los cuáles se habían multiplicado casi por $1,5^{12}$

\subsection{El retraso en la incorporación de los operadores virtuales}

A partir de 2000 el ministerio de Ciencia y Tecnología realizó varios intentos para aumentar el número de competidores en el mercado. Inicialmente se barajó la idea de conceder dos nuevas licencias GSM, pero esta medida se acabó aplazando

\footnotetext{
9 A pesar de ello, trató solucionar la situación multiplicando por nueve el canon por uso del espectro, pero la medida no prosperó por los recursos presentados por las operadoras y sus amenazas de dejar de invertir.

10 CMT (2001) señaló que las operadoras españolas tenían una alta rentabilidad y eran de las más caras de Europa, y a pesar de ello mantenían bajos niveles de inversión. En 2004 la CMT volvió a quejarse de que la competencia se reducía a las llamadas on-net y a las cuotas de abono.

11 Por ejemplo, el fabricante sueco Ericsson tuvo que reducir su plantilla a un tercio, y en España Xfera despidió prácticamente a la totalidad de sus 600 empleados.

12 Ver por ejemplo los informes anuales de la CMT y de AETIC.
} 
argumentando que esto limitaría el espectro de los operadores establecidos. Más tarde, en 2005, se aprovechó la liberación de espectro conseguida con el cierre de Moviline y de la telefonía rural celular (TRAC) para crear tres nuevas licencias GSM-900. El principal objetivo era mejorar el servicio en zonas con baja o nula cobertura (zonas rurales, proximidades a centrales nucleares y redes eléctricas, autovías y líneas del AVE), pero a su vez estas licencias daban una excelente oportunidad para crear un cuarto operador. Finalmente, no se aprovechó la ocasión y las licencias se adjudicaron a Telefónica y Amena; la expansión de la red permitió llevar el servicio, entre otros lugares, a 2.270 pueblos de menos de 50 habitantes.

La segunda medida lanzada por el gobierno español para aumentar la competencia fue la creación en 2001 de los operadores móviles virtuales (OMV). Uno de los principales atractivos de esta iniciativa era facilitar que los operadores de telefonía fija y de cable se convirtieran en operadores duales que pudiesen vender servicios móviles a través de las redes de los operadores existentes. Sin embargo, el gobierno dejó a la libre negociación entre las partes el establecimiento de los precios de interconexión. Como resultado, los OMVs y los operadores con redes propias no llegaron a acuerdos de roaming nacional. Era un fracaso previsible: no se puede aumentar la competencia y a la vez querer mantener la rentabilidad de los operadores existentes.

En los años siguientes se hizo patente que la ausencia de OMVs en España era una anomalía. En Europa, sólo España, Italia y Portugal carecían de OMVs a mediados de los 2000. Por eso a partir de 2007 la CMT intensificó sus esfuerzos para que este tipo de operadores entrasen en el mercado, fijando los precios, los plazos y los aspectos técnicos de la interconexión ${ }^{13}$. Y estas medidas tanto tiempo esperadas pronto dieron frutos: en 2008 Yoigo acordó con Telefónica el uso de su red de 2G y 3G (Yoigo es un operador de red, pero en la práctica funciona como un OMV), mientras que Happy y Carrefour hicieron lo mismo con Orange, y Euskaltel con Vodafone.

En la actualidad los OMVs tienen una cuota de mercado modesta, pero están erosionando rápidamente el oligopolio de Movistar, Vodafone y Orange, que mantienen la parte del león. En 2009 la cuota conjunta de mercado en líneas de los OMVs era del 3,1 por 100, que ya fue superior al 2,5 de Yoigo. Los datos trimestrales de la CMT muestran que en el cuarto trimestre de 2010 la cuota de mercado de los OMVs era del 4,6 por 100 y la de Yoigo del 4 por 100. La cuota de mercado en ingresos de estos operadores es menor debido a que sus clientes tienen un patrón de consumo más moderado que el resto ${ }^{14}$. No obstante, no hay duda de que estos operadores han

13 Telefónica interpuso un recurso contencioso-administrativo contra la obligación de alquilar sus redes aprobada por la CMT en 2006. La Audiencia Nacional lo desestimó el 12 de enero de 2009, recordando que la CMT regulaba «un mercado ya definido previamente por la Comisión Europea de conformidad con los principios establecidos en el marco regulador europeo», en la Directiva 2002/21/CE.

14 Algunos OMVs son completos y disponen de elementos de red propios, y otros, los que más crecen, son revendedores de tiempo de llamada. 
introducido una dinámica positiva en el funcionamiento del mercado, por lo que los operadores existentes se ven obligados a mejorar sus ofertas comerciales para retener a sus clientes.

En resumen, nuestro examen de la política de telecomunicaciones de las dos últimas décadas muestra que se han perseguido objetivos contradictorios como son el aumento del bienestar social (a través del aumento de la competencia) y el fomento de la industria nacional de las telecomunicaciones y la electrónica (a través de acciones destinadas a mantener la rentabilidad de los operadores). Esta dualidad ha llevado a incorporar menos operadores de los que hubiese sido posible (Cuadro 2). Y también ha generado una cierta debilidad del gobierno frente a las operadoras, como demuestra la no retirada de la licencia a Xfera tras sus reiterados retrasos para entrar en servicio ${ }^{15}$.

\section{Los resultados de la competencia}

En un mercado liberalizado los principales aspectos del servicio que valoran los consumidores son los precios, la calidad del servicio y las facilidades para cambiar de operador. Desde la aprobación del Paquete Telecom de 2002 la legislación europea no otorga a la CMT capacidad legal para influir directamente en los precios del móvil. Por este motivo, ante la constatación de que los precios en España son anormalmente altos la única opción de la CMT ha sido reducir de forma importante los precios de interconexión de terminación, con la esperanza de que los operadores trasladen la rebaja a los precios minoristas. Otra estrategia ha sido fomentar la entrada de los OMVs y facilitar el cambio de operador. Estas medidas deberían favorecer la competencia y reducir los precios, pero en la práctica sus efectos han sido menores de los esperados.

A continuación se analiza la evolución de los precios del móvil en los últimos años y la estrategia regulatoria adoptada por la CMT para reducir los precios de interconexión. También mostramos cuáles son las principales quejas de los usuarios relacionadas con la calidad del servicio según la información publicada por la Oficina de Atención al Usuario de Telecomunicaciones del Ministerio de Industria, Turismo y Comercio.

\subsection{La rigidez de los precios minoristas}

En España los precios de la telefonía móvil se liberalizaron en 1998, y además tras la aprobación del llamado Paquete Telecom en 2002 y de la Ley General de

\footnotetext{
15 El gobierno intentó que Xfera iniciara sus actividades, pero no le permitió vender su licencia ni se la retiró. Xfera notificó en junio de 2004 que pretendía empezar a operar en 2005, pero no lo hizo hasta años después.
} 
Telecomunicaciones en 2003 la CMT carece de autonomía para evaluar y regular el mercado minorista de comunicaciones móviles sin la autorización de la Comisión Europea ${ }^{16}$. Los únicos precios minoristas que están regulados en la actualidad en la telefonía móvil son los precios del roaming internacional, ya que en 2007 la Unión Europea quiso combatir directamente los grandes márgenes que las compañías mantenían en esta actividad. Esta medida supuso que por primera vez una autoridad supranacional fijara los precios de un servicio de telecomunicaciones de esta importancia. En 2009 la regulación del roaming internacional se prorrogó hasta 2012, y se amplió la regulación a los servicios de mensajes cortos (SMS) enviados a través de itinerancia internacional. El resultado fue una reducción significativa de los precios. Así, en España el ingreso por minuto de itinerancia internacional pasó de los 101,01 céntimos de euro por minuto en 2006 a los 70,43 céntimos por minuto en 2009.

Dejando aparte esta medida, en los últimos diez años no se ha planteado la necesidad de regular los precios de la telefonía móvil en España. Después de la desregulación de 1998 se consideró que la presencia de tres operadores ya era suficiente para disciplinar a los precios. Sin embargo, las expectativas no se cumplieron. Aunque en los años siguientes los precios en España se redujeron considerablemente, lo hicieron menos que en otros países europeos.

En la etapa del duopolio de Movistar y Airtel (Vodafone) entre 1995 y 1999 prácticamente no existió competencia porque el número de usuarios crecía a ritmos muy elevados y los operadores obtenían elevadas rentabilidades sin necesidad de competir en precios. Tras la desregulación de precios del GSM en 1998 empezaron a surgir descuentos selectivos a ciertos clientes y se generalizaron las tarjetas de prepago, lo cual produjo una caída media de precios del 17,8 por 100 en 1999.

La salida de Amena al mercado, apoyada por una regulación asimétrica, impulsó más si cabe el crecimiento del servicio. Entre 1999 y 2005 se pasó de 27,3 a 97,2 líneas por cada 100 habitantes, y en 2006 se sobrepasó la barrera del 100 por 100 de penetración. La competencia en el mercado hizo perder a Movistar entre 1998 y 2000 un 20 por 100 de cuota, de la que Amena absorbió 15 puntos y Airtel los 5 restantes. En los años siguientes, el mercado empezó a dar señales de saturación y Movistar y Airtel se vieron forzados a bajar precios y fidelizar a sus clientes mediante descuentos, premios y regalos de terminales. Incluso a partir de 2002 se llegó a hablar de guerras de precios, con los operadores respondiendo sistemáticamente a las bajadas de precios de sus rivales. En los precios desaparecieron las cuotas de abono y la regulación de la portabilidad facilitó que los usuarios empezaran a cambiar de compañía.

${ }^{16}$ El Paquete Telecom consta de cinco Directivas y una Decisión Comunitaria sobre el especto radioeléctrico. Establece que las agencias nacionales deben justificar la imposición, levantamiento o modificación de regulaciones en un mercado a partir del análisis del mismo, que debe seguir los criterios de la Comisión. Inicialmente había 18 mercados regulables, que después pasaron a 12, entre los cuales está el mercado mayorista de telefonía móvil, pero no el minorista. 
La reducción de precios se ha intensificado en los últimos años gracias a la regulación de los precios de terminación, el aumento de la competencia generado por los OMVs y la introducción reciente de tarifas planas. Si en 2000 el ingreso medio por minuto de tráfico era de 29,36 céntimos de euro para llamadas a fijo y de 23,52 céntimos para llamadas de móvil a móvil, en 2009 los ingresos para estos servicios son de 15,13 y de 12,92 céntimos de euro, es decir que en diez años los precios se han reducido a la mitad en términos nominales (Gráfico 5) ${ }^{17}$. Los datos trimestrales de la CMT muestran que en 2010 estas reducciones continuaron, posiblemente favorecidas por la crisis económica y por el aumento de operadores.

\section{GRÁFICO 5}

\section{INGRESOS MEDIOS POR MINUTO (CÉNTIMOS)}

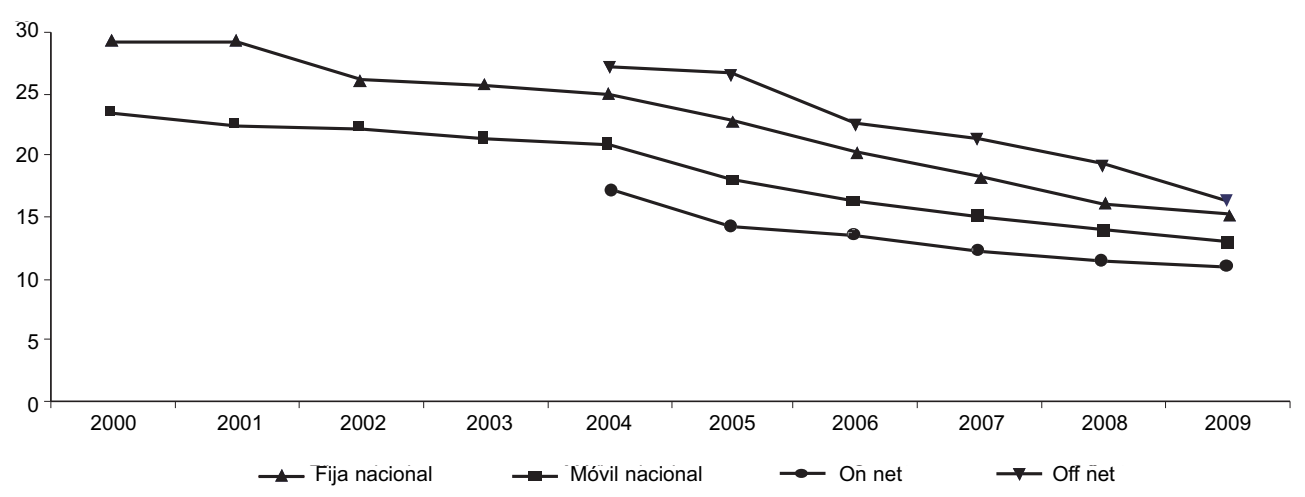

FUENTE: CMT, varios años.

Prácticamente todas las semanas hay nuevas ofertas para los nuevos clientes: regalos de terminales cada vez más sofisticados, tarifas a la carta, paquetes de mensajes a precio reducido, etcétera. Y al parecer estas estrategias están funcionando, porque se está reduciendo la proporción de usuarios de prepago a favor de los usuarios de contrato, debido a la convergencia de precios de las dos modalidades. Las líneas sin contrato llegaron a ser el 65 por 100 del total en 2001, pero fueron en torno al 40 por 100 en 2009. Los operadores se afanan por retener a sus clientes y captar los de la competencia, así como favorecer la migración de prepago a contrato, modalidad que ha llegado a representar el 80 por cien de los ingresos de explotación, ya que este tipo de usuarios realizan un mayor consumo del servicio.

\footnotetext{
17 Dada la gran variedad de tarifas, bonos y descuentos existentes en el mercado español, la CMT utiliza el ingreso medio por minuto de voz como aproximación a los precios ofrecidos por los distintos operadores en el mercado.
} 
La CMT (2010) muestra que en España un usuario de móvil cambia de operador cada 3,5 años en media. En general, los tres principales operadores tienen menos rotación, posiblemente porque consiguen fidelizar más a sus clientes subvencionando los terminales. El cambio de operador se ha visto favorecido por la utilización de la portabilidad del número de teléfono, especialmente a partir de la llegada de los OMVs. En España la portabilidad se realiza en 5 días en promedio y es gratuita, cuando en Europa se suelen tardar más de 8 días y los usuarios tienen que pagar por ella. Inicialmente la portabilidad favoreció a Vodafone pero desde 2007 los principales beneficiados han sido Yoigo y los OMVs, que prácticamente han conseguido todos los usuarios que han cambiado de operador buscando precios más bajos y tarifas sencillas. En 2009 se realizaron cerca de 460.000 portabilidades, el mayor número conseguido hasta ahora. De esta cantidad, Movistar perdió 154.000 y Vodafone 306.000. En cambio, Orange ganó 35.000, Yoigo 308.000 y el resto de OMV ganaron 116.000 clientes portados ${ }^{18}$. Para paliar esta situación, los operadores tradicionales han tratado de bajar los precios reduciendo el número de planes de descuento y las promociones especiales.

Pero a pesar de estos indicadores positivos, cuando se comparan los precios de España con los del resto de la Unión los resultados son desalentadores. Según muestra la Comisión Europea (2010) en su décimo cuarto informe, en 2008 el precio medio del tráfico de voz en las redes móviles de España fue de 0,17 euros $(0,19$ euros en 2007), por encima de la media europea de 0,13 euros, y el ingreso medio anual por usuario fue de 381 euros, por encima de la media europea de 323 euros (Gráfico 6). El informe señala que España es el país más caro de la UE según una cesta de consumo medio. Estas conclusiones son similares a las de la OCDE (2009), donde se muestra que los países de la OCDE con mayores precios son España, Estados Unidos y Canadá, igual para patrones de consumos bajos, medios o altos. Los países con precios más bajos son Finlandia, Países Bajos y Suecia (Gráfico 7). Varios especialistas en la medición de los precios en la telefonía móvil han destacado que los precios utilizados en los estudios de la OCDE y de la UE pueden tener problemas de construcción y de comparabilidad. Sin negar la importancia de esta crítica es importante destacar que la comparación internacional muestra que en España todavía existe margen para aumentar la competencia y lograr menores precios.

18 Euskatel, Carrefour, Lebara, Happy Móvil, Diamovil, R Cable, Eroski, Pepephone, Sweno, Ono, E-plus, Masmóvil, BT, Telecable, Jazztel y Hits. 
GRÁFICO 6

PRECIO MEDIO POR MINUTO DE VOZ, 2008

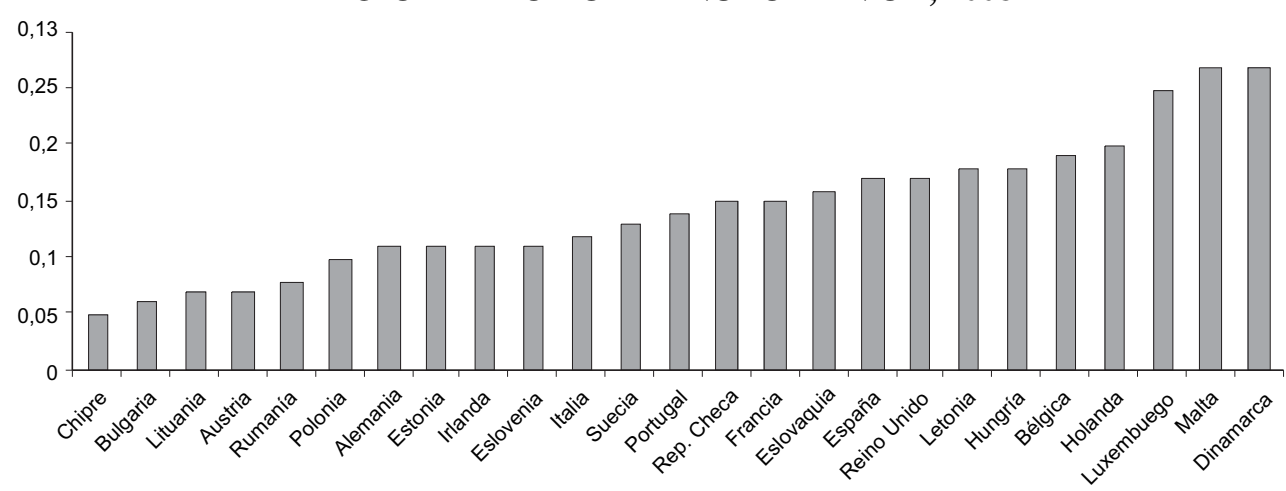

FUENTE: EUROPEAN COMMISSION (2010).

Precio minuto de voz

\section{GRÁFICO 7}

GASTO EN TELEFONÍA MÓVIL PARA UNA CESTA MEDIA DE LLAMADAS SEGÚN LA OCDE (AGOSTO DE 2008, IMPUESTOS NO INCLUIDOS, US\$, PPP)

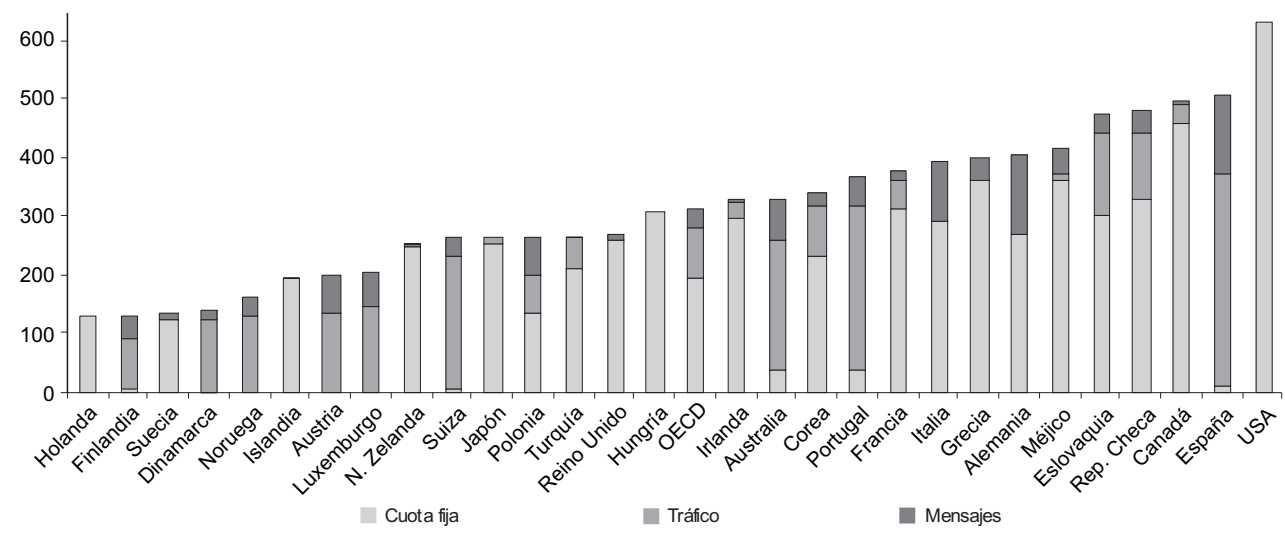

NOTA: La cesta utilizada no incluye descuentos o llamadas gratuitas a números pre-seleccionados. En la cesta de consumos medios se consideran 1.368 minutos. Estas se reparten en 780 llamadas (14 por 100 locales, 7 por 100 nacionales, 48 por 100 móviles on-net, 24 por 100 móviles off-net, 7 por 100 voice mail); 600 SMS (65 por 100 onnet, 35 por 100 off-net). De todas las llamadas, el 50 por 100 son en periodo pico, el 24 por 100 en periodo no-pico y el 26 por 100 en fin de semana. FUENTE: OCDE (2009). 


\subsection{Intensificación de la regulación de la interconexión}

Los reguladores de un mercado liberalizado disponen de pocos instrumentos para evitar que los operadores utilicen su poder de mercado para aumentar los precios minoristas. En la actualidad, la herramienta más importante de la que dispone la CMT para favorecer la competencia es la regulación de los precios de interconexión, también llamados de terminación porque son los precios que pagan los operadores cuando terminan sus llamadas en la red de sus rivales. Hasta ahora los precios de interconexión, especialmente los de llamadas procedentes de teléfonos fijos, han sido una de las principales fuentes de ingresos de los operadores de telefonía móvil. Con ellos han financiado sus planes de descuentos y el regalo de terminales, de modo que la interconexión actúa de hecho como una subvención de los usuarios de teléfonos fijos a los de móvil.

En España se empezó a regular la interconexión en redes móviles en 1997, cuando las autoridades europeas forzaron al gobierno a compensar a Airtel por haberle cobrado 510 millones de euros por su licencia de GSM, cuando no había cobrado nada a Movistar ${ }^{19}$. En 1999 también se autorizó a Amena a usar las redes de Movistar y Vodafone para facilitar su puesta en marcha. En cambio, cuando Xfera (Yoigo) salió al mercado la interconexión se dejó al albur de una negociación entre partes, igual que se hizo después con los OMVs, lo que dificultó que estos operadores pudieran iniciar sus actividades comerciales.

Desde 2000 los operadores españoles están obligados a publicar una Oferta de Interconexión de Referencia, y los operadores reconocidos como dominantes en interconexión tienen deberes que incluyen la separación contable de la interconexión, fijar precios de interconexión orientados a costes y aplicar el principio de transparencia y simetría de precios de interconexión ${ }^{20}$.

En los últimos años los precios de interconexión de terminación se han reducido en la mayoría de países de la UE, generalmente gracias a la introducción de mecanismos como el glide path que obligan a los operadores reducir progresivamente los precios. En España, entre 2006 y septiembre 2009 la CMT aplicó un glide path asimétrico que redujo en casi un 50 por 100 los precios de terminación de los cuatro operadores de móvil y de los nueve OMVs completos hasta alcanzar una media de 7,08 céntimos de euro, todavía por encima de la media europea de 6,7 céntimos de euro. El objetivo de esta medida fue favorecer el acceso al mercado de Xfera y los OMVs y el abaratamiento de los precios minoristas (Gráficos 8 y 9).

19 Resolución sobre modificaciones de la oferta de interconexión de referencia de Telefónica de España, S.A.U. de la CMT, Madrid, 2001. Véase también HERGUERA y AGUILAR (2001).

20 Movistar y Vodafone fueron declarados operadores dominantes en telefonía móvil e interconexión mediante la Resolución de la CMT de julio de 2000 (renovada el 5 de septiembre de 2002). Amena fue declarada operador dominante en septiembre de 2003. En 2007 Yoigo también fue declarado operado con poder significativo de mercado. 
GRÁFICO 8

INGRESOS MAYORISTAS TOTALES (MILLONES DE EUROS)

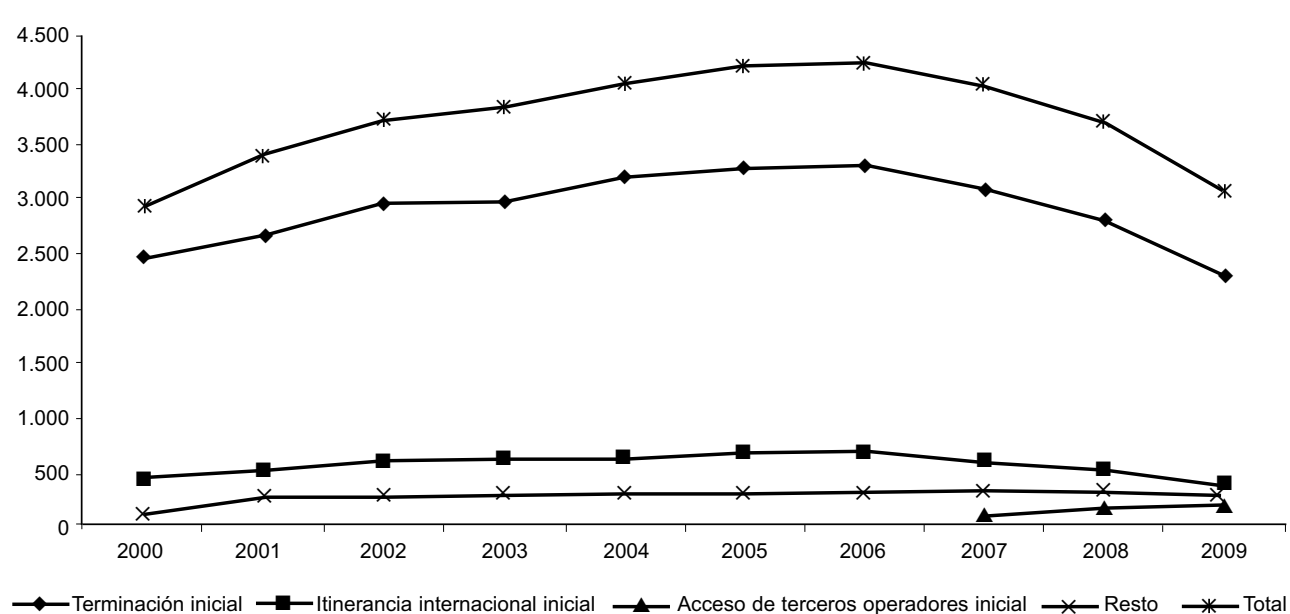

FUENTE: CMT, varios años.

GRÁFICO 9

INGRESOS MEDIOS POR TERMINACIÓN

(CÉNTIMOS/MINUTO Y CÉNTIMOS/MENSAJE)

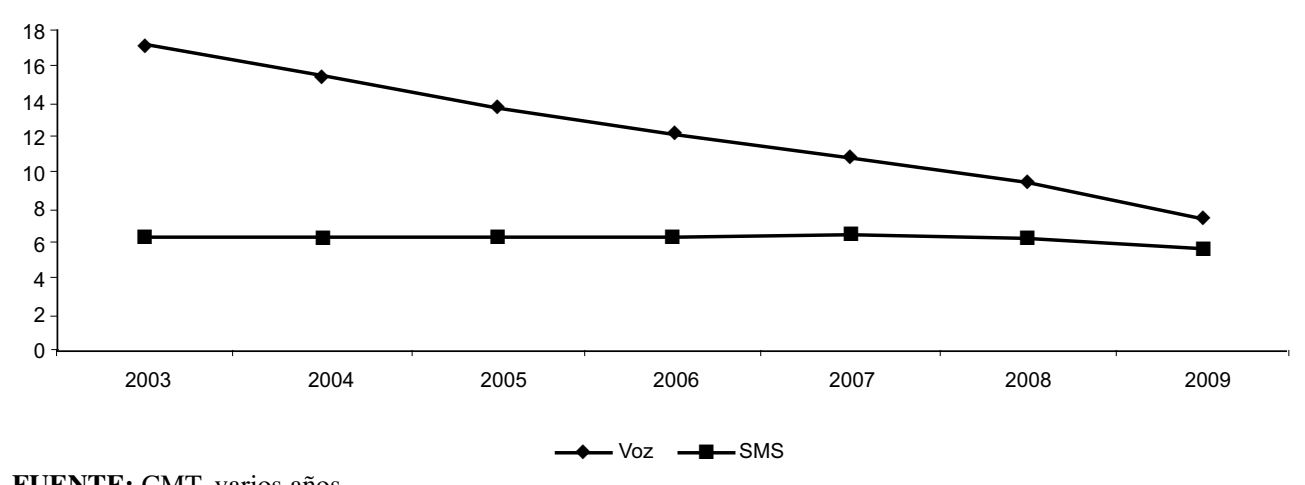

FUENTE: CMT, varios años. 
En 2009 la CMT estableció un nuevo glide path asimétrico para el periodo 20092012, que satisface la Recomendación de la Comisión Europea sobre precios de terminación. De este modo en abril de 2012 se habrá pasado de los 7 céntimos de euros que actualmente cobran Telefónica, Vodafone y Orange y sus OMVs a los 4 céntimos de euro, y de los 10,4 que cobra Yoigo a los 4,97 céntimos de euro. Esto supondrá una reducción cercana al 42 por 100 respecto al precio existente en $2007^{21}$.

Los precios de terminación de los cuatro operadores móviles son asimétricos. Durante mucho tiempo Orange cobró unos precios mayores que Movistar y Vodafone, pero cuando fue declarado operador dominante en el servicio e interconexión los precios de los tres operadores convergieron. Esta asimetría también se ha utilizado para apoyar la entrada de Yoigo. Cuando en 2007 el operador entró en el mercado la CMT le autorizó a cobrar 17 céntimos por minuto, frente a los 11,14 céntimos que se pagaban en sentido inverso. Esta regulación no fue muy bien recibida por la Comisión Europea, pero la CMT la encontró justificada porque Yoigo se incorporó al mercado más tarde que sus rivales, por lo que tiene menos clientes y sus costes son mayores.

Otra asimetría de los precios de terminación españoles es que los precios de fijomóvil han sido tradicionalmente más altos que los precios móvil-fijo, debido a que estos últimos están sometidos a un régimen de precios autorizados. En 2001 el ingreso medio por terminación de llamadas móvil-fijo era de 3 céntimos, mientras que las llamadas fijo-móvil pagaban ocho veces más. En 2009 el ingreso medio de terminación móvil-fijo fue de 0,7 céntimos, y el de fijo-móvil y móvil-móvil fue de 7,4 céntimos. A pesar de ello, el ingreso medio final que obtuvieron los operadores de fijo cuando hicieron llamadas a redes móviles fue de 17,4 céntimos de euro/minuto, mientras que si la llamada era de red móvil a fija el ingreso medio final obtenida por el operador móvil era de 15,1 céntimos de euro/minuto (CMT, 2010). Por tanto, las diferencias de precios de terminación no se reflejaron en los precios finales, lo cual evidencia que los operadores móviles tienen unos márgenes de retención mayores.

En resumen, la regulación de los precios de terminación tiene como objetivo que los menores costes de los operadores se trasladen a los usuarios a través de menores precios finales. Sin embargo, esta intervención tiene dos limitaciones. Por un lado, los precios de terminación sólo afectan a las llamadas off-net y por tanto tienen un efecto limitado en el precio final. Y por otro, en España los operadores tienen libertad para fijar sus precios minoristas, de modo que es sobre todo la competencia y no los precios de terminación lo que más influye en los precios finales. Ciertamente, en la última década la reducción de los precios de interconexión ha sido superior al 60 por 100. Aunque esta regulación ha favorecido la reducción de los precios minoristas, hay otros aspectos que inciden en su evolución, como el número de competidores.

${ }^{21}$ En octubre de 2009, Movistar, Vodafone, Orange y los OMV completos tenían un precio de terminación de 6,1 céntimos de euro, y Yoigo de 9,1. 


\subsection{La calidad del servicio}

Otro indicador importante que define la salud de la competencia es la calidad del servicio que reciben los consumidores. En este sentido cabe señalar que en España se ha diseñado un doble mecanismo de protección e información a los consumidores. Por una parte la Orden ITC 912/2006 de 29 de marzo, la llamada «orden de calidad», que desarrolla el Real Decreto 424/2005, de 15 de abril, por el que se aprobaba el Reglamento de condiciones de servicio y la protección a los usuarios de servicios de telecomunicaciones, contiene una amplia regulación en cuanto a la medición de la calidad del servicio, los deberes de información sobre calidad que hay que dar a los consumidores en el momento de contratar, la obligación de los operadores de publicar periódicamente datos sobre los niveles de calidad ofrecidos y medidos y el tratamiento de las situaciones en que los niveles reales no se ajusten a los comprometidos.

El Ministerio de Industria, Comercio y Turismo supervisa y publica la información sobre calidad ofrecida por los operadores, y elabora informes de seguimiento de calidad. También ha elaborado, en colaboración con el CIS, un estudio sobre percepción de la calidad por parte de los usuarios de las telecomunicaciones ${ }^{22}$, del que se deduce que en general las percepciones de los usuarios sobre las deficiencias del servicio tienen más que ver con el desconocimiento de lo que han contratado que con carencias del servicio en sí.

La otra vía de protección a los consumidores es la Oficina de Atención al Usuario de Telecomunicaciones (OAUT), que tiene su origen en el artículo 8.3 del RD 1554/2004 de 25 de junio, que contiene la estructura orgánica del Ministerio de Industria, Comercio y Turismo. La OAUT forma parte de la Dirección General de Telecomunicaciones y Tecnologías de la Información, y tiene una doble función: resolver las controversias entre los operadores y los usuarios de las telecomunicaciones -incluida la propuesta de resolución de las reclamaciones- y proporcionar atención e información a los consumidores. Vemos, por tanto, que se pretende resolver la asimetría de información existente en este tipo de servicios creando un sistema ágil de gestión de las reclamaciones y un mecanismo específico de atención a los consumidores.

La existencia de esta doble vía de medición y control refleja el interés por la calidad del servicio en un momento en el que la expansión del sector es muy acelerada. Los datos existentes (Gráfico 10) muestran que entre 2005 y 2010 las reclamaciones referentes a problemas con teléfonos fijos han pasado de sextuplicar las relativas a móviles (el 61 por 100 del total frente al 10 por 100) a ser menos de la tercera parte (por debajo del 17 por 100 frente al 52 por 100).

22 http://www.mityc.es/telecomunicaciones/es-ES/Servicios/CalidadServicio/Documents/ Estudio_QoS_percibida.pdf 


\section{GRÁFICO 10 \\ PORCENTAJE DE RECLAMACIONES POR TIPO DE SERVICIO}

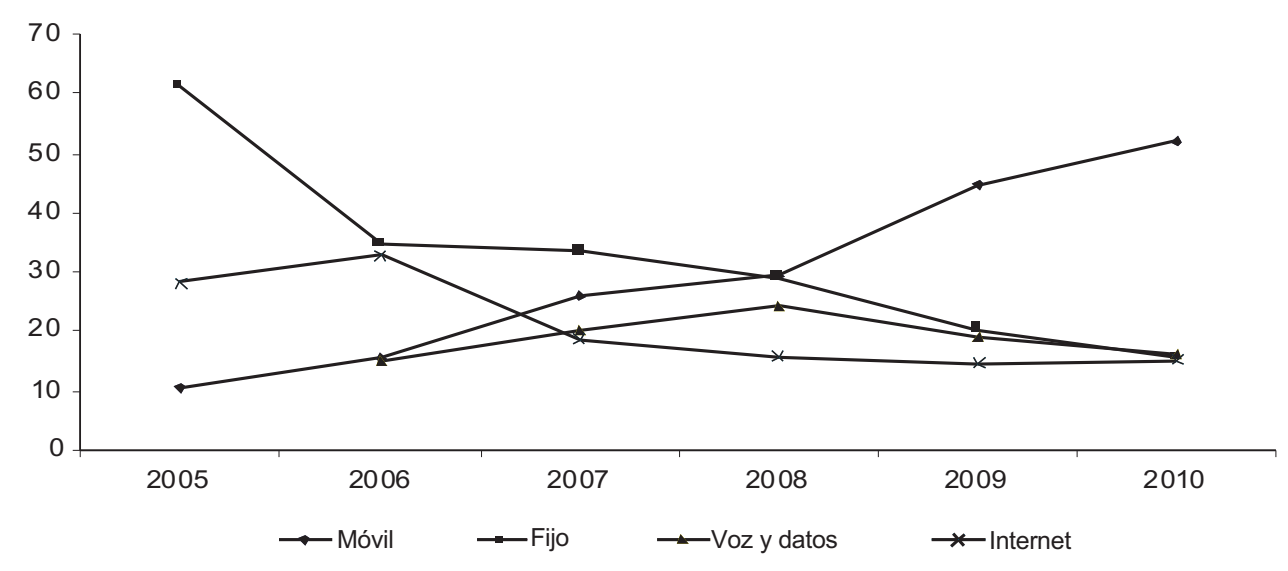

FUENTE: OAUT, varios años.

Centrándonos en el subsector de la telefonía móvil, resulta notable el hecho de que las reclamaciones que afectan directamente a características de la prestación del servicio -cobertura, interrupciones y mensajería- están siempre por debajo del 25 por 100 del total, llegando algún año a descender casi hasta el 5 por 100 (el promedio de los seis años es en torno al 15 por 100), mientras que el grueso de las quejas recibidas se refieren a la parte administrativa -facturación, portabilidad, etc.-, que oscilan entre el 64 y el 80 por 100. La mitad de todas las reclamaciones tienen que ver con la facturación y más de una cuarta parte con el proceso para darse de alta o de baja como cliente de un operador (Gráfico 11).

\section{GRÁFICO 11 \\ PORCENTAJE DE RECLAMACIONES EN LA TELEFONÍA MÓVIL, POR TIPO DE RECLAMACIÓN}

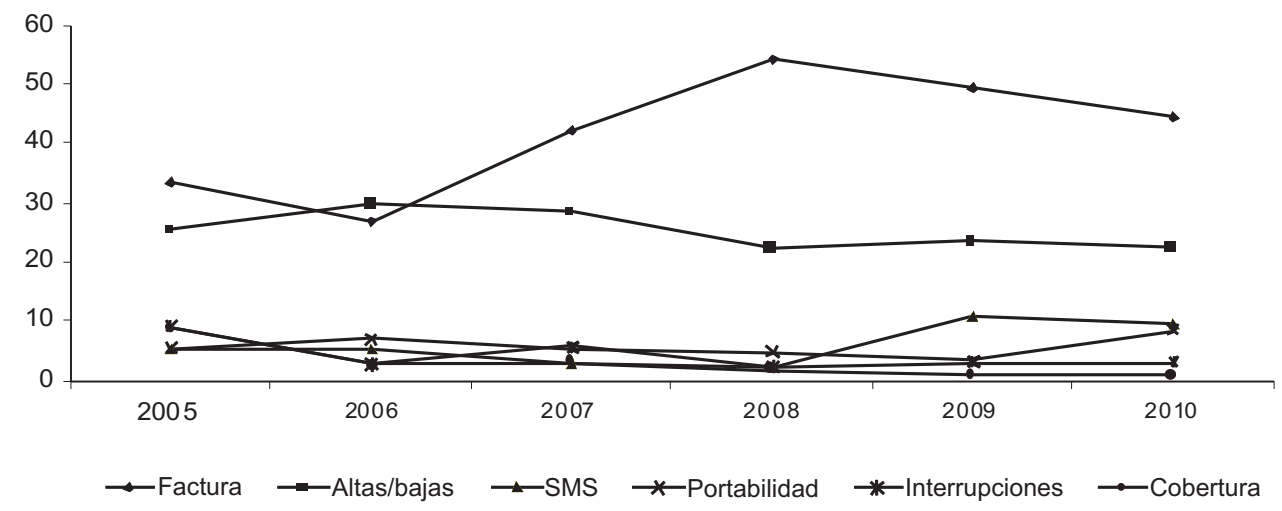

FUENTE: OAUT, varios años. 
En definitiva, si nos atenemos a la opinión de los consumidores descontentos que reclaman a la OAUT, los niveles de satisfacción de los usuarios del móvil son elevados, sobre todo en cuanto al funcionamiento del servicio. Pero al mismo tiempo el número relativo de reclamaciones (es decir, ponderado por el número de abonados de cada operador) no ha dejado de crecer, especialmente a partir de la entrada en funcionamiento en 2007 de Yoigo, operador que excepto en el primer semestre de 2010 ha tenido una media de quejas superior a la de sus rivales (Gráfico 12).

\section{GRÁFICO 12 \\ RECLAMACIONES POR CADA 1.000 USUARIOS}

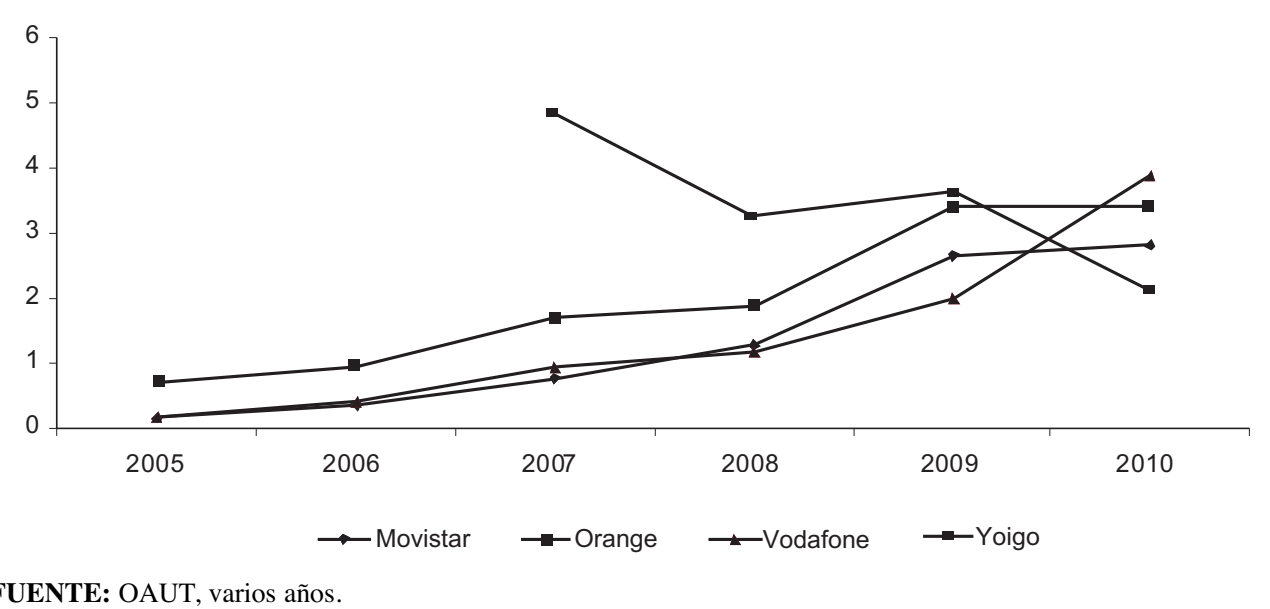

\section{El futuro del sector: banda ancha y nuevos servicios}

En los últimos años, el desarrollo de tecnologías como el GPRS y el UMTS ha generalizado el uso de mensajes cortos, mensajes multimedia, el acceso a internet, el tráfico de datos en general y el uso del móvil como medio de pago. De este modo, mientras que en 2005 los datos representaban el 2,5 por 100 de los ingresos de la telefonía móvil en 2009 esta cifra había aumentado hasta el 10 por 100. De hecho, en 2009 los ingresos por datos crecieron un 35 por 100, mientras que el total de ingresos de la telefonía móvil se redujo en un 4 por 100.

De todos estos servicios, uno de los que más éxito ha tenido es el Internet móvil ya que muchos usuarios de los operadores desean no sólo navegar desde sus móviles, sino descargar contenidos y ver películas. En 2009 casi el 17 por 100 de los accesos a la banda ancha en España ya se hacían a través de redes 3G/UMTS. Generalmente los usuarios de móvil navegan por Internet a través de datacards que se conectan al ordenador o mediante el propio teléfono móvil si el usuario tiene una subscripción que le permite acceder a banda ancha. 
La penetración de las conexiones de alta velocidad que se contratan para uso compartido con el servicio de telefonía móvil es ya de 6,1 subscriptores por cada 100 habitantes, y los usuarios disponen de contratos muy variados en cuanto a duración, limitaciones de descarga y servicios a los que pueden acceder.

Por otro lado, en 2009 las líneas de datacards (UMTS y HSDPA) vinculadas exclusivamente a Internet móvil tuvieron una penetración del 4,2 líneas por cada 100 habitantes. Estas líneas tienen una tarifa específica de datos y sólo se pueden utilizar para el acceso a datos a alta velocidad. De este modo los ingresos derivados de las líneas sólo de datos son mayores que las subscripciones para acceder a datos a alta velocidad que se realizan complementariamente a la telefonía móvil. Con todo, la penetración en España de estos servicios es todavía menor que la otros países europeos.

Un aspecto esencial para el fomento del acceso a la banda ancha en el móvil es la existencia de terminales con nuevas capacidades y de una oferta de contenidos nuevos y atractivos, como por ejemplo la posibilidad de ver los canales de televisión digital terrestre. Otro aspecto básico es que los operadores dispongan de espectro suficiente para poder prestar el servicio en condiciones de calidad aceptables. A continuación analizamos estos dos temas.

\subsection{Nuevas aplicaciones y contenidos}

Un aspecto clave para la industria del móvil es saber qué servicios se suministrarán en el futuro y cómo afectaran a los modelos de negocio de los operadores. Muchas empresas como Apple, Google, Nokia y Palm se están posicionando en el mercado de Smart Phones. Además de permitir a la gente hacer llamadas o consultar su correo electrónico, los Smart Phones son plataformas que integran programas informáticos diseñados por empresas independientes (agendas, libros electrónicos, etcétera). Apple por ejemplo tiene cerca de 50.000 aplicaciones para su iPhone, mientras que Blackberry tiene unas 1.000. Estas aplicaciones se pueden descargar fácilmente a través de las online stores de empresas como Apple, Microsoft y Nokia. $\mathrm{Al}$ igual que sucede con los ordenadores, los usuarios tienen libertad para descargar aplicaciones e instalarlas en sus móviles.

A medida que los terminales de móvil se van convirtiendo en ordenadores, los ordenadores portátiles también se convierten en teléfonos móviles. La convergencia entre estos dos soportes se debe a que el precio de las conexiones de acceso a Internet se está reduciendo y a que la velocidad de conexión aumenta a medida que los operadores mejoran sus redes. La convergencia también se ve favorecida por la rápida reducción de los precios de los netbooks. En efecto, algunos operadores incluso los regalan con los contratos de banda ancha.

En los próximos años será importante analizar si estos cambios pueden llevar a los operadores de móvil a perder el control de su negocio. Cada vez más, los usuarios utilizan las aplicaciones que quieren y acceden a los contenidos que les apetecen a través de sus dispositivos, y los operadores se están convirtiendo en meros 
conductos por los que circula el tráfico de Internet. Estas transformaciones suponen que el mercado pasa de tener un pequeño número de operadores integrados verticalmente a la separación vertical entre varias capas tecnológicas: redes, terminales, sistemas operativos y aplicaciones. En este nuevo mundo los operadores móviles convencionales tendrán que compartir sus ingresos y beneficios con proveedores de software y servicios como Apple, Google y Facebook.

Otro problema a tener en cuenta es la elevada utilización de los nuevos servicios, que consumen mucha capacidad de las redes. Para evitar estos problemas los operadores podrían dar a algunos paquetes de información (tráfico de Internet) prioridad sobre otros (como transmisión de ficheros). Es decir, ante las limitaciones en la capacidad de transmisión es posible que el principio de net neutrality -en virtud del cual la red funciona como un soporte que no distingue entre contenidos, sitios y plataformas, ni hay degradación de unas comunicaciones por otras- tenga menos opciones de mantenerse en el móvil que en el tráfico de Internet en las redes fijas.

\subsection{El dividendo digital}

El desarrollo del Internet móvil en España se puede ver facilitado por el llamado «dividendo digital», que consiste en la liberación de espectro en las frecuencias entre 790 y $862 \mathrm{MHz}$ derivada del apagón de la televisión analógica del 3 de abril de 2010 y de la implantación de la TDT, que precisa menos banda para sus emisiones. Se considera que esta banda de frecuencias, junto con los $190 \mathrm{MHz}$ que permanecen libres de la banda de $2,6 \mathrm{GHz}$, debería ofrecer a los operadores espectro suficiente para satisfacer la nueva demanda de comunicaciones de banda ancha. Las nuevas frecuencias se podrán usar para ofrecer nuevos servicios, mejorar la calidad de los móviles en movimiento, aumentar la penetración en grandes edificios o cubrir una mayor parte del territorio a un coste menor.

La Comisión Europea ha fomentado el uso del dividendo digital para la banda ancha móvil, intentando además que se haga de manera ordenada y armonizada. El objetivo primario es dar pautas técnicas homogéneas para una asignación de frecuencias que evite las interferencias y facilite el desarrollo de Internet móvil. Según la «UE-2020 Strategy», se pretende que a finales de 2013 haya acceso universal a la banda ancha.

Aunque la UE procura optimizar el uso del dividendo, son los Estados miembros los que han de asignar el espectro. En 2009 Miguel Sebastián, ministro de Industria, presentó un Real Decreto para asignar a la telefonía móvil el dividendo digital a partir de 2015, pero en junio de 2010 el gobierno acordó adelantar el cambio a 2013. Francisco Ros, responsable de Telecomunicaciones y Sociedad de la Información en el ministerio, anunció en 2011 que se licitarían nuevas licencias de 4G con frecuencias de $310 \mathrm{MHz}$, lo que según él convertía a España en el primer país con un plan completo para gestionar la totalidad del espectro asignado a los móviles ${ }^{23}$.

\footnotetext{
23 Véase, por ejemplo, El Mundo, de 5 de julio de 2010.
} 
En la práctica, no obstante, reordenar el sector no será nada sencillo porque una parte de la banda de 790-862 MHz que se quiere reasignar a los operadores de móvil se asignó hace poco tiempo a algunos canales de TDT, por lo que habrá que mover esos canales a otra frecuencia y volver a adaptar las instalaciones receptoras de los edificios. Según el ministerio, los costes de este segundo apagón -las televisiones habrán de emitir en dos frecuencias durante la transición y los usuarios habrán de adaptar las antenas- serán financiados por el Estado mediante la recaudación resultante de la venta del nuevo espectro a los operadores de móviles.

Estos problemas tienen probablemente una doble causa. La primera es que el apagón analógico fue precipitado por la voluntad del gobierno de adelantarse a otros países, y no se debatió adecuadamente qué se haría con el dividendo digital (García Leiva, 2009). La segunda es que no se ha cumplido la Ley General de Telecomunicaciones de 2003, que establecía la creación de una Agencia Estatal de Radiocomunicaciones especializada en la gestión del espectro. Estas funciones siguen en la subdirección general de Planificación y Gestión del Espectro Radioeléctrico, dentro de la dirección general de Telecomunicaciones. La gestión del espectro está regulada en la Orden ITC 332/2010 de 12 de febrero, en la que se aprueba el Cuadro Nacional de Atribución de Frecuencias (CNAF). La citada Orden prevé la reserva de parte del espectro para ciertos servicios, el establecimiento de preferencias de uso por razones de utilidad social, la delimitación de las bandas, canales y frecuencias que se reservan para el uso de los poderes públicos y la previsión de la explotación futura de las bandas bajo el principio de neutralidad tecnológica. En realidad la observación del CNAF muestra básicamente que la gestión del espectro en España se ajusta con exactitud a los estándares fijados en el Reglamento de Radiocomunicaciones de la UIT.

Otro aspecto fundamental, a la vista de nuestra anterior evaluación del sector de telefonía móvil en España, es saber como se adjudicarán las nuevas licencias de 4G en 2011. Alemania subastó las licencias de 4G en marzo de 2010 y obtuvo 4.384 millones de euros, frente a los 6.000 millones que se esperaban. Los Países Bajos también han realizado sus subastas con resultados igualmente discretos, lo que parece indicar cierto desinterés en la 4G en general y en las frecuencias subastadas de 2,6 $\mathrm{GHz}$ en especial, ya que las pujas se han centrado en los $800 \mathrm{MHz}$. Los analistas atribuyen estos flojos resultados a la crisis económica y a la lenta amortización de las inversiones realizadas para extender la 3G. Finalmente, el gobierno británico quiere que la subasta de licencias $4 \mathrm{G}$ se realice a finales de 2011. También se espera que en 2011 se realicen subastas de espectro para la 4G en Dinamarca, Suecia, Noruega y Francia.

\section{Conclusiones}

A la vista de los datos sobre el nivel de penetración del servicio, el crecimiento de la actividad y los resultados de las empresas parecería que la historia de la telefonía 
móvil en España es la historia de un éxito. No obstante, este éxito queda bastante matizado si comparamos el mercado español con los de otros países europeos similares, ya que aquí el desarrollo de la competencia parece haber sido sensiblemente inferior. En términos generales se puede decir que los consumidores españoles han pagado precios más altos y disfrutan de peor servicio que los de otros países.

Nuestra hipótesis sobre la débil competencia en la telefonía móvil en España descansa sobre dos explicaciones complementarias. La primera, basada en la economía política de la regulación, es que desde mediados de los noventa los operadores establecidos se beneficiaron de una excesiva protección, en buena parte justificada por las autoridades por la necesidad de impulsar la expansión del servicio. La otra explicación se basa en la teoría de la organización industrial y consiste en destacar que el número de operadores móviles en el mercado español ha sido demasiado reducido durante demasiado tiempo. En definitiva, la falta de operadores y la laxitud con la que fueron regulados impidió durante años el desarrollo de la competencia.

En primer lugar, hemos mostrado que en los noventa el regulador español mantuvo con los operadores establecidos una conducta dubitativa y tímida a la hora de desregular los precios minoristas y de promocionar la competencia. Inicialmente se consideró necesario garantizar la rentabilidad de las empresas para permitirles $-\mathrm{y}$ exigirles- una rápida expansión de sus redes en todo el territorio. A finales de los noventa la euforia por el rápido crecimiento del mercado disimuló la falta de competencia. Cuando se denunciaba que los precios eran demasiado altos las autoridades respondían que la pronta saturación del mercado disciplinaría a los operadores y causaría una guerra de precios que repercutiría directamente en el bienestar de los consumidores. Pero la saturación no se produjo, y el crecimiento sostenido del mercado frustró la aparición de la esperada competencia y la consiguiente caída de precios. En los últimos años se ha intentado corregir los precios excesivos, pero como la nueva legislación europea impide regular directamente los precios minoristas el principal instrumento que puede utilizar la CMT es la regulación de la interconexión. Esta estrategia no ha sido suficiente para situar los precios en unos niveles parecidos a los del resto de países europeos.

En segundo lugar, hemos explicado que la falta de competencia también está relacionada con las sucesivas decisiones de mantener un número reducido de operadores. La escasez de competidores se podía haber resuelto con la llegada en 2000 de Xfera, el cuarto operador, pero varios factores frustraron esta oportunidad. Ciertamente, la crisis de las punto.com y los problemas técnicos del UMTS no facilitaron el lanzamiento del nuevo operador. Pero no esta claro que estos factores justifiquen por qué la empresa no salió al mercado hasta 2008 , ni por qué durante todo este tiempo ni los gobiernos del PP ni los del PSOE fueron capaces de forzar la entrada en funcionamiento de Xfera ni de retirarle la licencia. Aunque sea mera especulación, parece sensato creer que si desde 2000 hubiese habido un cuarto operador el grado de competencia en España y el bienestar de los consumidores serían mayores.

En definitiva, nuestra conclusión es que la competencia en el mercado de telefonía móvil en España, y por añadidura el bienestar de los consumidores, ha sido víc- 
tima tanto de la fuerte expansión del mercado, que durante años moderó la rivalidad entre operadores, como de una desacertada estrategia regulatoria, que inicialmente apostó por limitar el número de operadores y mantener su rentabilidad. Sólo en los últimos años se han introducido medidas eficaces para aumentar el nivel de competencia y reducir los precios, como la regulación de la interconexión y el apoyo a los OMVs.

De cara al futuro parece que los operadores deberán esforzarse en mejorar la calidad de los servicios que ofrecen, especialmente a raíz de la generalización del acceso a la banda ancha móvil. Será crucial la existencia de contenidos y aplicaciones atractivas que sean accesibles a través de los terminales móviles. También será fundamental el aprovechamiento óptimo del llamado «dividendo digital», es decir, el espectro radioeléctrico liberado tras la implantación de la TDT. Las primeras subastas europeas de licencias de 4G han revelado menos interés por parte de los operadores del que se esperaba. Pero los datos disponibles permiten esperar un consumo creciente de nuevos servicios que, de confirmarse, podría producir una importante transformación de la estructura y del funcionamiento del mercado.

\section{Referencias}

[1] AGAR, J. (2003): Constant Touch, a Global History of the Mobile Phone. Icon Books UK, Duxford, Cambridge, UK.

[2] ALABAU, A. (1998): La Unión Europea y su política de telecomunicaciones. En el camino hacia la sociedad de la información. Fundación Airtel Móvil.

[3] ALABAU, A. (2001): La Unión Europea y su política para la Sociedad de la Información. En el umbral de una nueva gobernanza europea. Fundación Airtel-Vodefone.

[4] BEL, G. y COSTAS, A. (2001): «La privatización y sus motivaciones en España: de instrumento a política». Revista de Historia Industrial, O (19/20), 113-132.

[5] CABRAL, L. y SALANT, D. (2009): Evolving Technologies and Standards Regulation, mimeo.

[6] CALVO, A. (2010): Historia de Telefónica: 1924-1975. Primeras décadas: tecnología, economía y política. Ariel y Fundación Telefónica.

[7] CALZADA, J. y COSTAS, A. (2011): La economía política de la liberalización de las telecomunicaciones: ¿control de la inflación o universalización del servicio?, mimeo.

[8] CMT (1998): Informe Anual 1997, Comisión del Mercado de las Telecomunicaciones, Madrid.

[9] CMT (2001): Informe Anual 2000, Comisión del Mercado de las Telecomunicaciones, Madrid.

[10] CMT (2010): Informe Anual 2009, Comisión del Mercado de las Telecomunicaciones, Barcelona.

[11] DUNNEWIJK, T. y HULTÉN, S. (2007): «A Brief History of Mobile communications in Europe». Telematics and Informatics, 24, 164-179.

[12] EUROPEAN COMISSION (2010): «Progress Report on the Single European Electronic Communications Market (15th Report)», COM (2010), 253.

[13] FUENTELSAZ, L.; MACÍAS, J. P. y POLO, Y. (2008): «The evolution of Mobile 
Communications in Europe: The transit form the second to the third generation». Telecommunications Policy, 32, 436-449.

[14] GARCÍA LEIVA, M.-T. (2009): «El dividendo digital: desafíos, oportunidades y posiciones nacionales RLCS». Revista Latina de Comunicación Social, 64.

[15] GRUBER, H. y VALLETTI, T. (2003): «Mobile telecommunications and regulatory frameworks», en Emerging telecommunications networks: the international handbook of telecommunications economics, volume II, Editor(s): Madden, Cheltenham, Edward Elgar.

[16] GRUBER, H (2005): The Economics of Mobile Telecommunications, Cambridge University Press.

[17] HERGUERA, I. y AGUILAR, J. (2001): «Competencia por el abonado y competencia por el tráfico. Tarificaciones en la telefonía móvil en España», en Revista del Derecho de las Telecomunicaciones e Infraestructuras de Red, número extraordinario, «Móviles».

[18] JORDANA, J. y SANCHO, D. (1999): «Opciones de regulación y opciones de intervención: las políticas públicas de telecomunicaciones», en Jacint Jordana y David Sancho (eds.), Políticas de Telecomunicaciones en España. Colección de Ciencias Sociales. Serie de Ciencia Política, Tecnos.

[19] LAFFONT, J.-J. y TIROLE, J. (2000): Competition in Telecommunications. The MIT Press

[20] MOPTMA (1994): La liberalización de las telecomunicaciones en España, Secretaría General de Telecomunicaciones, MOPTMA.

[21] NORIEGA, R. y ARIÑO, G. (2004): «La liberalización y competencia en las telecomunicaciones: Balance 1998-2003», en Gaspar Ariño (dir.), Privatizaciones y liberalizaciones en España: Balance y resultados (1996-2003), tomo IV, Fundación de Estudios de la Regulación, Editorial Comares, Madrid-Granada.

[22] PRAT, A. y VALLETTI, T. (2003): «Spectrum Auctions Versus Beauty Contests: Costs and Benefits», en Mario Baldassarri y Luca Lambertini (eds.), Antitrust, Regulation and Competition, Palgrave Macmillan, Londres.

[23] ROMEO, J. M. y HUIDOBRO, J. M. (2006): «El ímpetu de la telefonía móvil», en Crónicas y testimonios de las telecomunicaciones españolas, tomo I, COIT, Madrid.

[24] SALANT, D. y WAVERMAN, L. (1998): The use of Standard Setting ad a Mean of Facilitating Cartyels and its Trade Effects, International Competition Policy Advisory Committee, U.S. Departarment of Justice.

[25] SANCHO, D. (1999): «La regulación de la telefonía móvil en España: Ideología e instituciones», en J. Jordana y D. Sancho (eds.), Políticas de Telecomunicaciones en Espa$\tilde{n} a$. Colección de Ciencias Sociales. Serie de Ciencia Política, Tecnos.

[26] SANZ, A. (1999): «Debate político y marco regulador de las telecomunicaciones en España», en Jacint Jordana y David Sancho (eds.), Políticas de Telecomunicaciones en España, Colección de Ciencias Sociales, Serie de Ciencia Política, Tecnos, Madrid. 